\title{
Copper Tailing Flocculation in Seawater: Relating the Yield Stress with Fractal Aggregates at Varied Mixing Conditions
}

\author{
Matías Jeldres ${ }^{1}$, Eder C. Piceros ${ }^{2}$, Norman Toro ${ }^{3,4, *}$, David Torres ${ }^{3,4}$, Pedro Robles ${ }^{5}$, \\ Williams H. Leiva ${ }^{1}$ and Ricardo I. Jeldres ${ }^{1, *}$ \\ 1 Departamento de Ingeniería Química y Procesos de Minerales, Facultad de Ingeniería, \\ Universidad de Antofagasta, Antofagasta 1240000, Chile; mjeldresvalenzuela@gmail.com (M.J.); \\ wleivajeldres@gmail.com (W.H.L.) \\ 2 Faculty of Engineering and Architecture, Universidad Arturo Pratt, Iquique 1100000, Chile; \\ edpicero@unap.cl \\ 3 Departamento de Ingeniería Metalúrgica y Minas, Universidad Católica del Norte, Antofagasta 1270709, \\ Chile; David.Torres@sqm.com \\ 4 Department of Mining, Geological and Cartographic Department, Universidad Politécnica de Cartagena, \\ 30202 Murcia, Spain \\ 5 Escuela de Ingeniería Química, Pontificia Universidad Católica de Valparaíso, Valparaíso 2340000, Chile; \\ pedro.robles@pucv.cl \\ * Correspondence: ntoro@ucn.cl (N.T.); ricardo.jeldres@uantof.cl (R.I.J.); \\ Tel.: +56-552-651-021 (N.T.); +56-552-637-901 (R.I.J.)
}

Received: 12 November 2019; Accepted: 29 November 2019; Published: 1 December 2019

\begin{abstract}
The implications of physical conditions of the feedwell on the rheological properties of synthetic copper tailings, flocculated in seawater, were analysed. The mixing intensity of flocculation was related to the structural characteristics of the aggregates, and the outcomes were linked to the yield stress of the pulp sediments. Tailings settling assays were conducted by using a $30 \mathrm{~mm}$ turbine type stirrer with an in-situ aggregate size characterisation. The structural characteristics of the aggregates were determined by using the focused beam reflectance measurement (FBRM). After a mixing time between the pulp and the flocculant, the sample was allowed to settle for $2.5 \mathrm{~h}$, where the variation of the sediment height was minimal. The sediment was gently removed and subjected to rheological characterisation. The yield stress was measured on an Anton Paar MCR 102 rheometer (ANAMIN Group, Santiago, Chile), with a vane-in-cup configuration. The mixing intensity was related to the characteristics of the aggregates, and the outcomes were linked to the yield stress of the flocculated pulp sediments. More aggressive hydrodynamics deteriorated the structure of the aggregates, promoting the reduction of both its size and the fractal dimension. This brought direct consequences on the rheological properties of the sediments: at higher mixing level, the yield stress was lower. The explanation lies in the structural changes of the aggregates, where at a fixed mixing rate, the yield stress presented a seemingly exponential increase over the fractal dimension. Additionally, correlations were found between the rheological properties with settling rate and aggregate size.
\end{abstract}

Keywords: seawater; copper tailings; rheology; fractal aggregates; thickening

\section{Introduction}

The recovery and succeeding reuse of processed water is essential to guarantee the sustainability of the copper mining industry, and it is directly associated with operational and environmental costs 
of the mineral processing. Water recovery is principally accomplished in thickeners, where chemical reagents (i.e., flocculants) are used to stimulate the decantation of solid particles, generating a clarified supernatant liquid [1]. The discharge is carried out by a lower cone (underflow), and it must be expelled with the help of rakes that move with the application of mechanical torque. The magnitude of the rheological properties is critical, and several studies show a qualitative improvement in dewaterability as a result of raking the suspension [2,3]. Ultimately, the thickened tailings are transported through pipes to a disposal area for subsequent dehydration and consolidation [4].

Tailings produced in the copper mining operations generally have clays contents like kaolinite, where their colloidal size and amorphous structure cause varied challenges in thickening. Usually, the settling rate of the flocculated slurries drop [5-7], and the rheological parameters can rise to acquire non-Newtonian behaviours [8,9]. Several studies have examined the adsorption of polyacrylamides on the surface of kaolinite, standing out as the main flocculants and most common clay that appear in the copper industry. It has been concluded that polymer adsorption occurs mostly on the kaolinite edge, that is, on the broken bonds of the aluminol (Al-OH) and silanol ( $\mathrm{Si}-\mathrm{OH})$ groups, through hydrogen bonds $[10,11]$.

Depending on the physical and chemical conditions throughout the flocculation process, the aggregates may confer significant structural differences (size, porosity, shape, etc.). Several studies reveal the influence of mixing intensity on the structure of the flocculated aggregates [12,13]. Overall, by increasing the slurry shearing, the initial mixing and aggregation rates may enhance, but this ultimately leads to a reduced final aggregate size due to the extended breakage. Vaezi et al. [14] flocculated kaolinite suspensions with A-PAM (Magnafloc $\left.{ }^{\circledR} 1011\right)$ at constant mixing intensity $\left(145 \mathrm{~s}^{-1}\right.$ ) and varied mixing time. Initially, large porous aggregates were obtained, with sizes that even reached 1000 $\mu \mathrm{m}$. As the flocculation time elapsed, the aggregates reduced in size due to their fragmentation. The authors noted a monotonous trend between aggregate porosity (or effective density) and its diameter. The diversity of structures that flocculated mineral aggregates may take directly impacts the rate at which particles settle. For example, spherical agglomerates frequently deposit faster than non-spherical ones, although those that are needle-shaped settle quicker if the major axis remains vertical [15]. Porous aggregates have high hydrodynamic profiles. Then, the more significant drag considerably lessens their sedimentation rate compared to solid particles of the same size [16]. However, aggregates still deposit faster than individual fine particles.

A central feature to discern the performance of thickening operations is the rheological behaviour of the thickened slurries [17]. The knowledge and adequate control of the rheological properties allow optimising the energy consumption required to drain the thickener underflow, and this is directly related to the torque that must be applied to the rakes so that they work. The yield stress, which corresponds to the minimum stress required to cause a material to flow, is determined by the solid concentration and the strength of the particle networks. In this sense, Zhou et al. [18] found a direct relationship between yield stress with the adhesion forces between the mineral surfaces, which was determined by a Nanoscope III atomic adsorption microscope. The authors analysed flocculated silica surfaces for combination of polymer type and dosage, and the bond strength proved to be strongly influenced by the chemical conditions of the mineral surface and solution like $\mathrm{pH}$, salinity and polymer characteristics. This agrees directly with the work reported by Johnson et al. [19], who interpreted the results of the yield stress for concentrated pulps of alumina, zirconia and kaolin, considering different types of interaction forces. The authors reviewed the classic sum of van der Waals' interaction with the double electrical layer; however, the surface complexity of the minerals led to incorporate non-DLVO (Derjaguin, Landau, Verwey, Overbeek) interactions such as hydration, hydrophobic and steric forces. Additionally, Neelakantan et al. [20] studied the effect of the mixing intensity on the structure of the kaolinite aggregate and the yield stress of the sediment when the particles were flocculated with PAM. The researchers noted that rising the agitation rate of the slurry causes a considerable reduction in yield stress as well as the size of the aggregates. It was explained that the aggregates are possibly squeezed under intense mixing, diminishing their apparent volume in solution. 
It is interesting to comprehend the interplay of concentrated slurries in saline environments since the use of seawater is an option that is being increasingly used by the copper mining industry. Salinity alone is not a significant problem for concentration operations; when working at natural $\mathrm{pH}(\mathrm{pH} 8$ approx.), impressive recoveries of copper and molybdenum can be achieved in flotation stages [21-23]. It is noteworthy considering that a desalination plant by reverse osmosis leads to diverse financial and environmental concerns. For example, reverse osmosis (RO) plants commonly return hypersaline water to the sea, where the consequences to the marine life can be significant considering the high concentrations of ions and precipitating complexes $\left(\mathrm{CaCO}_{3}, \mathrm{CaSO}_{4}, \mathrm{BaSO}_{4}\right)$. Additionally, the high temperature of the stream $\left(30-40^{\circ} \mathrm{C}\right)$ increases the toxicity of metals and chemical $[24,25]$.

Recently, Reyes et al. [26] proved the notable implication of seawater on the yield stress of magnetite tailings. For this, they used mixtures of seawater with process water, and the results were associated with measurements of zeta potential. Jeldres et al. [27] studied the yield stress and viscoelasticity of kaolin sediments of slurries flocculated with an anionic polyelectrolyte of high molecular weight. The authors found that pulps fixed with low salinity led to a rise in sediment yield stress, while increasing the $\mathrm{NaCl}$ concentration the yield stress diminished. This behaviour was interpreted in terms of the DLVO theory, where compressions of the ionic cloud that surround the particles surfaces and functional groups of the polymer produced aggregates with a weaker structure at high salinity. This phenomenon was shown later by molecular dynamics simulations, considering the interaction between a polyacrylamide with a quartz surface, varying the salt concentrations [28].

To date, several studies show the influence of mixing degree during flocculation on suspension dewatering [29-31] and, consequently, the relationship between the structure of the aggregates with the settling rate $[32,33]$. However, few systematic studies deepen in the relationship between the microscopic properties over the rheological behaviour of the underflow in thickening stages. The most relevant work was recently developed by Benn et al. [34], who performed turbulent flocculation in a large-scale pipe reactor (slurry flows $25 \mathrm{~L} \mathrm{~min}^{-1}$ ). The authors analysed the yield stress profile from the bottom to the top of the sediment and related the outcomes to the solids concentration. Additional information was presented on the influence of flocculant management. In this context, our research aims to analyse the implications of physical conditions of the feedwell on the rheological properties of the underflow of flocculated clay-based tailings in seawater. The mixing intensity was related to the structural characteristics of the aggregates, and the outcomes were linked to the yield stress of the flocculated pulp sediment. The results provided in this study are of interest to the copper mining industry, especially those that use seawater in their operations.

\section{Methodology}

\subsection{Materials}

Quartz particles purchased from DondeCapo (Santiago, Chile) were used, where the $\mathrm{SiO}_{2}$ content estimated by X-Ray diffraction (XRD) analysis was greater than $99 \mathrm{wt} . \%$. A D5000 X-ray diffractometer (Siemens S.A., Lac Condes, Chile) was used and the data were processed with Total Pattern Analysis Software (TOPAS) (Siemens S.A., Lac Condes, Chile). The mean square chord length, determined by the focused beam reflectance measurement (FBRM) probe, was $24 \mu \mathrm{m}$. The kaolin particles were acquired from Ward's Science (Rochester NY, USA), and the XRD indicated a composition of $84 \%$ Kaolinite and $16 \%$ Halloysite. The mean square chord length was $12 \mu \mathrm{m}$.

Seawater was collected from San Jorge Bay in Antofagasta (Chile) and was filtered at $1 \mu \mathrm{m}$ using a UV filter system (BIO\&NAM, Santiago, Chile), to defeat its bacterial activity. The ionic composition was determined with varied chemical methods depending on the ion type. By atomic absorption spectrometry: $\mathrm{Na}^{+} 10.9 \mathrm{~g} / \mathrm{L}, \mathrm{Mg}^{2+} 1.38 \mathrm{~g} / \mathrm{L}, \mathrm{Ca}^{2+} 0.4 \mathrm{~g} / \mathrm{L}, \mathrm{K}^{+} 0.39 \mathrm{~g} / \mathrm{L}$. The composition of $\mathrm{Cl}^{-}$was determined by argentometric method and it was $19.6 \mathrm{~g} / \mathrm{L}$. The concentration of $\mathrm{HCO}^{3-}$ was determined by acid-base volumetry, whose value was $0.15 \mathrm{mg} / \mathrm{L}$. Seawater showed a conductivity of $50.4 \mathrm{mS} / \mathrm{cm}$ at $25^{\circ} \mathrm{C}$. The $\mathrm{pH}$ of the slurries was fixed at $\mathrm{pH} 8$ with sodium hydroxide. 


\subsection{Flocculation Test: Aggregate Size and Settling}

Flocculation experiments were conducted using a PTFE, $30 \mathrm{~mm}$-diameter turbine type impeller at the end of vertical shaft (diameter $4 \mathrm{~mm}$ ) within a $1 \mathrm{~L}$ capacity, $100 \mathrm{~mm}$ diameter vessel (see Figure 1 ). The base of the impeller was positioned $20 \mathrm{~mm}$ above the vessel's bottom surface. A volume of liquid $(232.2 \mathrm{~mL})$ was transferred to the vessel, with known masses of the solid phases then added as dry powders to give mixtures containing $92.3 \mathrm{wt}$.\% quartz and $7.7 \mathrm{wt} . \%$ kaolin at the required total solid concentration. The suspension was preconditioned by mixing at $450 \mathrm{rpm}$ with a laboratory stirring IKA EUROSTAR 60 Control (WReichmann, Santiago, Chile) for $30 \mathrm{~min}$. After this period, the mixing rate was reduced according to the test (from 100 to $300 \mathrm{rpm}$ ), and diluted flocculant was added to give the required dosage, with the mixing maintained for a further required flocculation time (from 10 to $80 \mathrm{~s}$ ). The flocculated suspension was then carefully transferred into a stoppered cylinder $\left(300 \mathrm{~cm}^{3}\right.$ volume, $35 \mathrm{~mm}$ internal diameter), which was inverted twice by hand (the entire cylinder rotation process taking $\sim 4 \mathrm{~s}$ in all cases). The fall of the mudline, defined as the suspension-supernatant interface, was monitored for one hour and the settling rate taken as the initial linear slope of a plot of the mudline height against time.

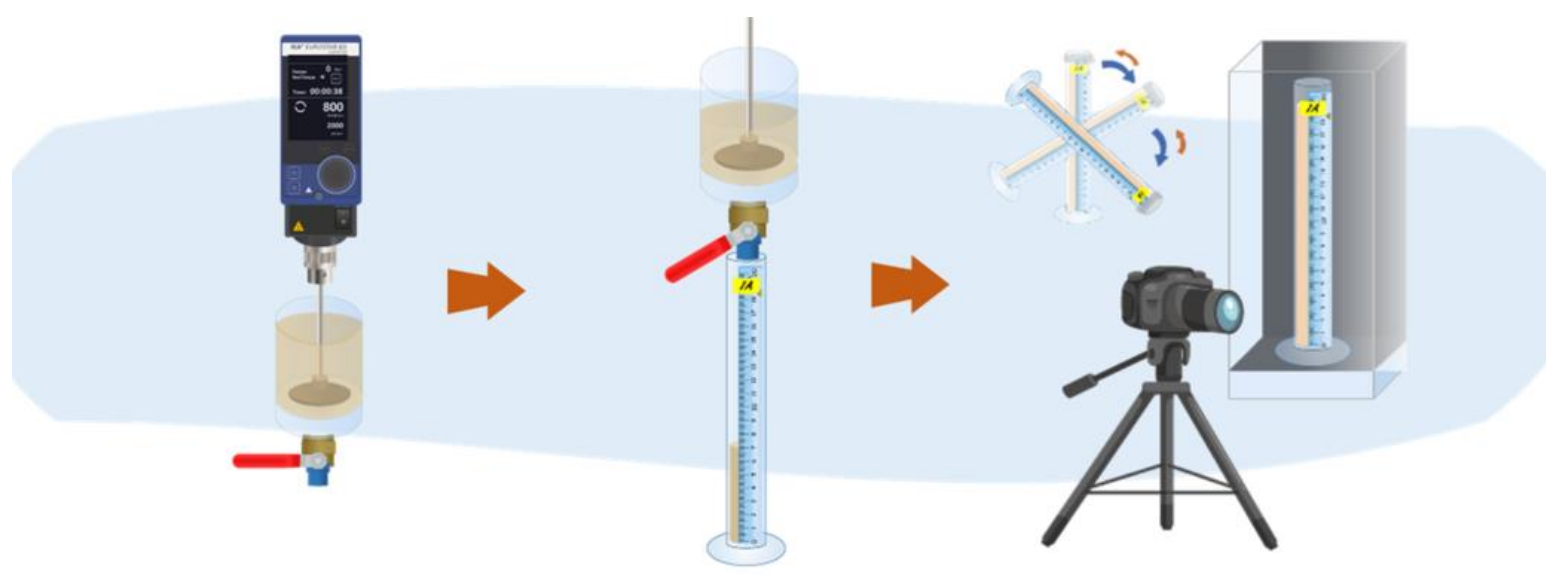

Figure 1. Schematic representation of experimental setup for settling assays.

The size distribution of the primary and aggregate particles was recorded using the Particle Track G400 equipment that uses Mettler Toledo's focused beam reflectance measurement (FBRM) technology. The measurement began with the tracking of the primary particles of the copper tailings and culminated three minutes after the polymer addition.

\subsection{Yield Stress of Sediment}

After $2.5 \mathrm{~h}$ of sedimentation, the supernatant liquid was gently removed and the lower cylinder separated (containing the sediment of the column). The yield stress was determined by employing the vane-in-cup configuration, with the stress-strain method. The measurements were carried out on an Anton Paar MCR 102 rheometer (ANAMIN Group, Santiago, Chile) and the RheocompassTM Light version software processed the data (ANAMIN Group, Santiago, Chile). The diameter of the vane was $2.2 \mathrm{~cm}$ and that of the cup was $4.2 \mathrm{~cm}$.

\subsection{Fractal Dimension}

The aggregates usually have scale-invariant properties, allowing them to be characterised by a simple parameter: the fractal dimension. This parameter is directly linked to the porosity of the aggregates, and its value may range from $D_{f}=1$ (for a one-dimensional line) up to 3 (solid body of three dimensions). As for flocculation, an aggregate with fractal dimension $D_{f}=3$ would match to a solid sphere. The calculation of the fractal dimension is made with Equation (1) [33] and requires entering 
the values of the hindered settling rate and aggregate size. Both 'input' variables were obtained through the experiments described in Section 2.2.

$$
U_{h}=\frac{\overline{d_{a g g}^{2}} g\left(\rho_{s}-\rho_{l}\right)\left(\overline{\frac{d_{a g g}}{\overline{d_{p}}}}\right)^{D_{f}-3}}{18 \mu}\left(1-\varphi_{s}\left(\frac{\overline{d_{a g g}}}{\overline{d_{p}}}\right)^{3-D_{f}}\right)^{4.65}
$$

$U_{h}$ : Hidered settling rate, $\mathrm{m} / \mathrm{s}$

$d_{\text {agg: }}$ : Diameter of aggregate, $\mathrm{m}$

$d_{p}$ : Diameter of prymere particle, $\mathrm{m}$

$\rho_{s}$ and $\rho_{l}$ : Density of solid and liquid phase, respectively, $\mathrm{kg} \mathrm{m}^{-3}$,

$g$ : Gravity acceleration constant, $\left(9.81 \mathrm{~m} / \mathrm{s}^{2}\right)$

$\mu$ : Fluid viscosity, $\mathrm{Ns} / \mathrm{m}^{2}$

$\varnothing_{s}$ : Volumetric solid concentration

$D_{f}$ : Fractal dimension of mass length.

\section{Results}

\subsection{Aggregate Size}

Figure 2 shows the chord length distributions (CLD) of aggregates composed of synthetic tailings in seawater at $\mathrm{pH} 8$. The square-weighted distributions reflect a volume-weighting and will be more influenced by the contribution of any aggregates formed. FBRM provides a distribution of particle chords, unlike a conventional distribution based on diameters, however Heath et al. [35] proved that the mean or mode averages of the square-weighted chord lengths are comparable to conventional sizing over the range from 50 to $400 \mu \mathrm{m}$. The onset of fine particle aggregation from flocculation would typically be expected to induce a shift to the right in CLDs; however, Figure 2 displayed a variation to the left while for increased mixing time. This is explained because of the irreversible fragmentation of the aggregates while they are subjected to the hydrodynamics shearing, and the finite duration that flocculants remain adsorbed on the particle surfaces. It is expected that the breakage will be more intense in larger structures; therefore, the differences are attenuated after a certain period when few large-aggregates remain in the system. For this reason, the shift to the left of the size distribution is attenuated as time progresses.

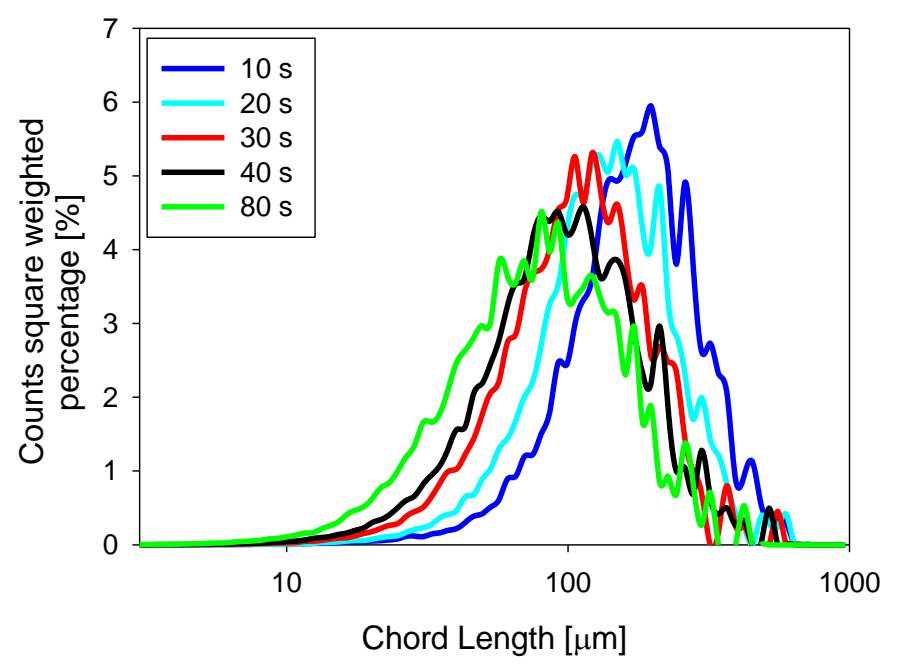

Figure 2. Square-weighted chord length distribution of flocculated copper tailings in seawater at varied flocculation time ( $\mathrm{pH} 8,225 \mathrm{rpm})$. 


\subsection{Analysis of Yield Stress}

The vigour at which the slurry is mixed with the polymers is determined by the agitation rate, quantified by the impeller revolutions per minute ( $\mathrm{rpm}$ ) and the mixing time. These variables are crucial for the aggregation since they allow to ensure particle-particle collisions, and they form the basis for the proper design of thickener feedwells [36]. Figure 3 presents the effect of the mixing intensity through flocculation on the yield stress of the sediment separated after $2.5 \mathrm{~h}$ that the tailings sediment. The trend given is clear: higher mixing intensity leads to lower yield stress values. For example, the yield stress taken at $100 \mathrm{rpm}$ for $10 \mathrm{~s}$ was higher than $300 \mathrm{~Pa}$, while after an intensive stirring of $300 \mathrm{rpm}$ for $80 \mathrm{~s}$, the value was close to $150 \mathrm{~Pa}$. Interestingly, no relevant differences in the solid concentration of sediment were distinguished concerning the various disturbances imposed to the system and mostly oscillates between $42-44$ wt. \% (see Table 1), without showing clear trends regarding the mixing variables. Accordingly, the performance of the yield stress observed in Figure 3 is explained by the structural changes of the particle aggregates, as a product of changing the mixing intensity. Stronger agitations cause a more significant breaking of bonds between the particle/aggregate networks that make up the slurry, before the sedimentation process. This causes the aggregate structures to be more fragile and open that is consistent with the characterisation of the fractal dimension, which is described later.

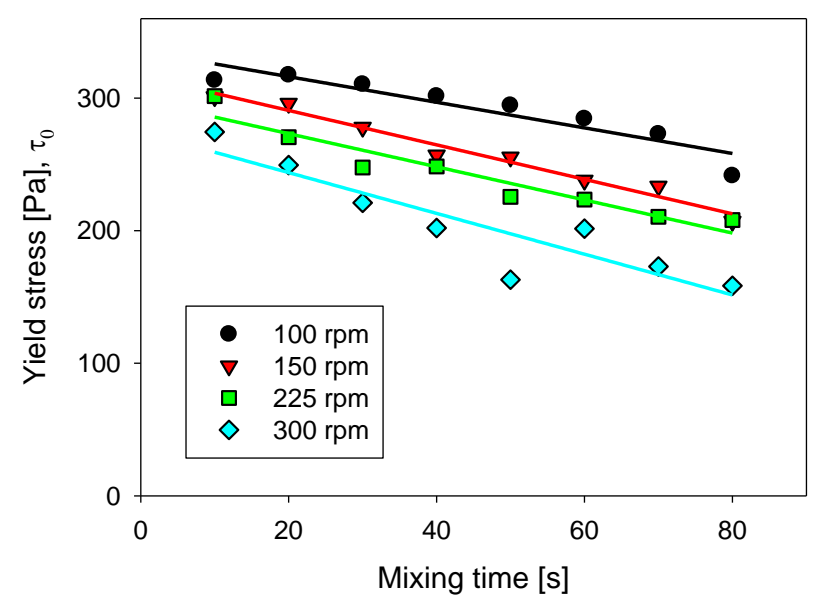

Figure 3. Yield stress of tailing sediment in seawater at varied flocculation time and mixing rate (flocculant dose: $14 \mathrm{~g} /$ tonne, $\mathrm{pH} 8$, sedimentation time: $2.5 \mathrm{~h}$ ). The experimental data are extracted from Table 1.

Figure 4 displays the relationship between the yield stress of the sediment and the average size of the aggregates that are formed after the flocculant addition. For a fixed mixing rate, a larger aggregate size leads to higher yield stress. The trend is similar for the all mixing rates examined in this research (from 100 to $300 \mathrm{rpm}$ ). However, care should be taken when relating only the aggregate size, since it is essential to consider the physical conditions in which they were formed. For example, aggregate with a mean chord length of 100 microns causes higher yield stress if it is built at a mixing rate of $300 \mathrm{rpm}$ instead of $150 \mathrm{rpm}$. The reagent dosage is also relevant: at a higher amount of polymer, the yield stress is larger. This is illustrated in Figures 7 and 8.

The relationship between aggregate size and yield stress coincides with that proposed by Neelakantal et al. [20], who studied the effect of shearing kaolinite sediments, flocculated with polyacrylamide copolymers. The authors based their explanation on the elimination of retained water within the porous aggregates as a result of the fragmentation caused by shearing. This would create a dramatic reduction in the apparent volume of solids in the suspension. However, unlike the assays executed by Neelakantal et al., our work based on studying the mixing intensity on flocculation, that is, before the sedimentation begins; therefore, the structural behaviour between both studies differs. 


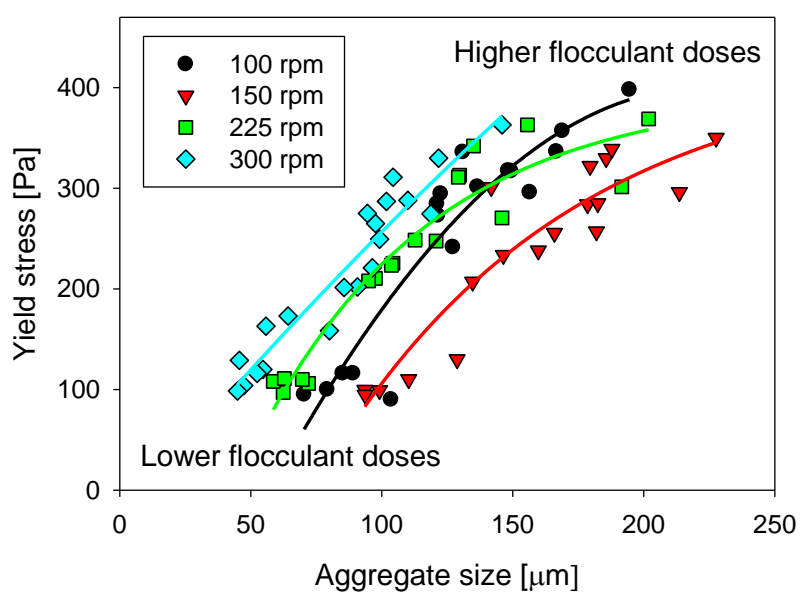

Figure 4. Relationship between yield stress of tailing sediment in seawater and aggregate size (mean chord length). The experimental data are extracted from Table 1.

Figure 5 gives the connection between fractal dimension and yield stress when the flocculation is carried out at different mixing rates. An apparent decrease in the fractal dimension is generated with the increase of the mixing, which is agreeable with that declared by Deng and Davè [37], who state that when aggregates are produced with a higher shear rate, they grow irregularly, resulting in lower fractal dimensions. On the other hand, more aggressive hydrodynamics deteriorates the structure of the aggregates, promoting the reduction of the fractal dimension.

At a fixed mixing rate, the yield stress presented a seemingly exponential increase over the fractal dimension. This agreement with the proposed by Deng and Davè [37], who established that a lower fractal dimension leads to a lower mechanical strength of the agglomerate, which was determined by the model proposed by Kendall and Stainton [38]. The authors considered the porosity, adhesion work and particle diameter. Zhou et al. presented two interesting works that directly links the rheological properties with the interaction forces $[18,39]$. The authors used an atomic force microscope to record the interaction forces between silica surfaces in solutions with cationic polyelectrolytes of different electric charge. The magnitude of adhesion force was related to the strength of the particle networks that make up a silica slurry. Interestingly, it was found that the strength of aggregates has a direct relationship with the rheological properties of the pulps.

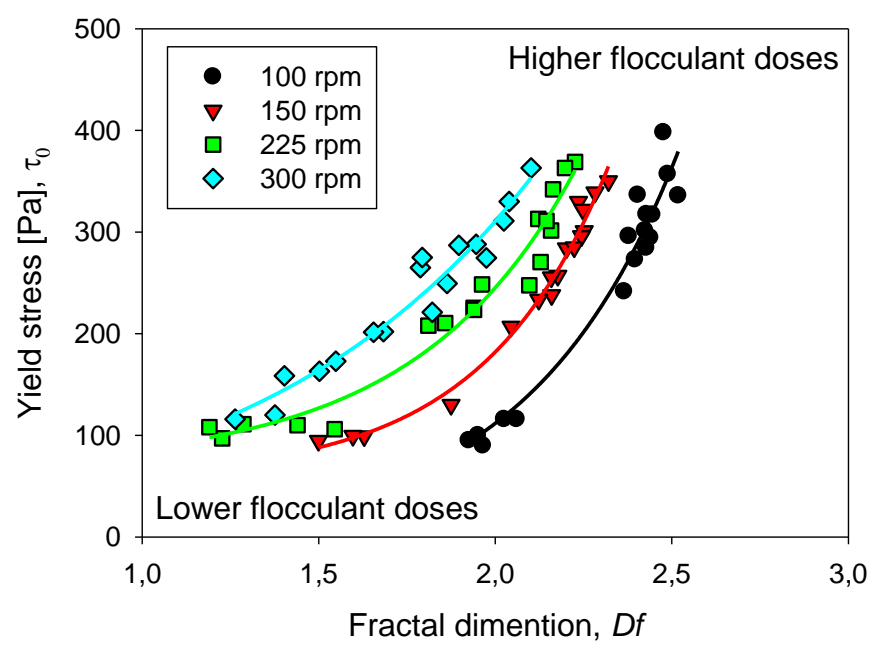

Figure 5. Relationship between yield stress of tailing sediment in seawater and fractal dimension of aggregates. The experimental data are extracted from Table 1. 
The sedimentation rate of a suspension is strongly determined by the size and structure of the aggregates that compose it. For the same size, more compact structures have higher settling rates than open and porous have [40]. In this sense, it is expected that aggregates with larger fractal dimensions settle faster. In parallel, the structural aggregate features define the rheological behaviour of a suspension, so it is assumed that there is a close correlation among the settling rate and the rheology of the sediment, as shown in Figure 6: An increase in the settling rate was accompanied by higher yield stress. This result has a significant practical utility since there are continuous attempts in the mining industry to optimise the recovery of water from thickening stages, whose search generally lies in raising the sedimentation rate while maintaining low yield stress values in the thickener underflow. Then, to sustain proper thickener control, it is crucial to understand that both parameters are closely linked and the decisions that operators make inevitably impact both.

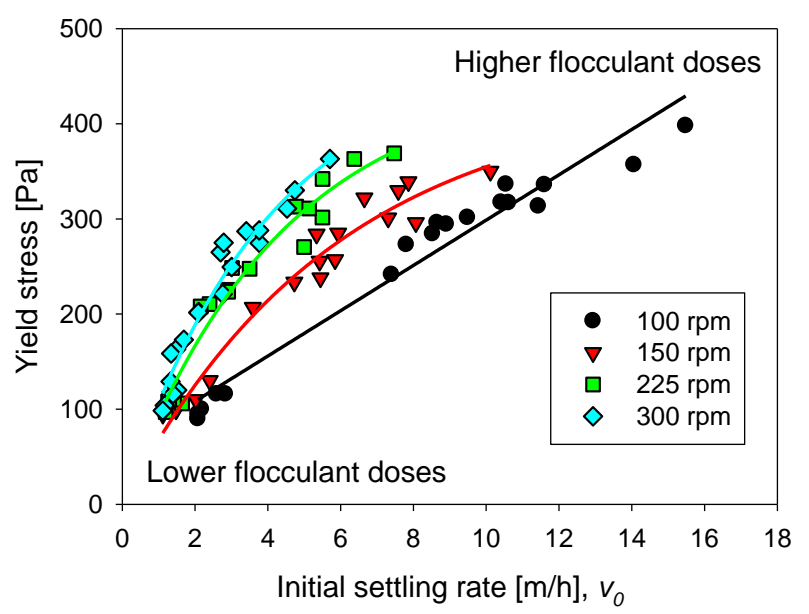

Figure 6. Relationship between yield stress of tailing sediment in seawater and settling rate. The experimental data are extracted from Table 1.

The flocculant dose was a key part of all the cases examined. An extract of the experimental data developed in the present work is shown in Figure 7, which shows a clear tendency of the rheology regarding the dosage of the polymer. A higher amount of polymer molecules leads to a greater amount of bonds that bind the particles, generating higher yield stress. On the other hand, the higher polymer dosage produces aggregates with a more robust structure, causing an increase in its fractal dimension (Figure 8), as previously reported by Ofori et al. [41].

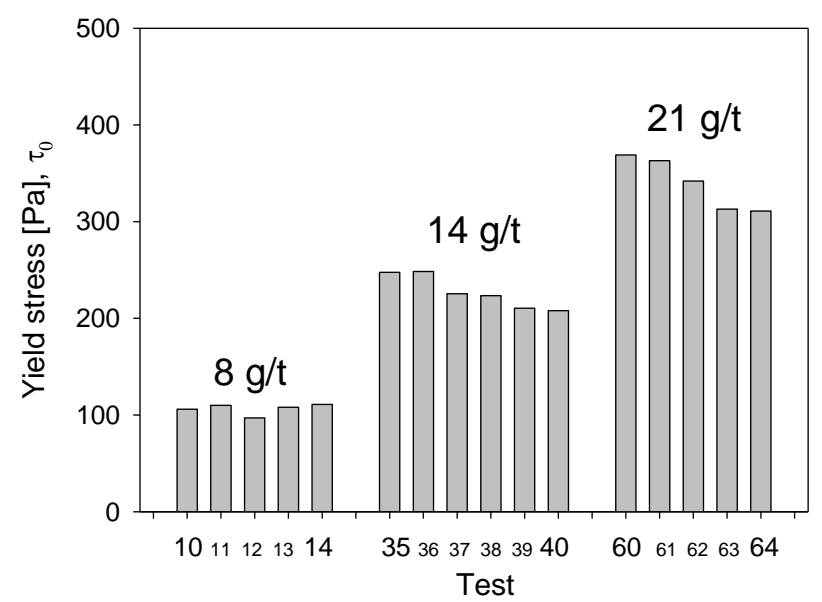

Figure 7. Influence of flocculant dose on yield stress of tailing sediment in seawater. The tests numbered in abscissa are according Table 1. 


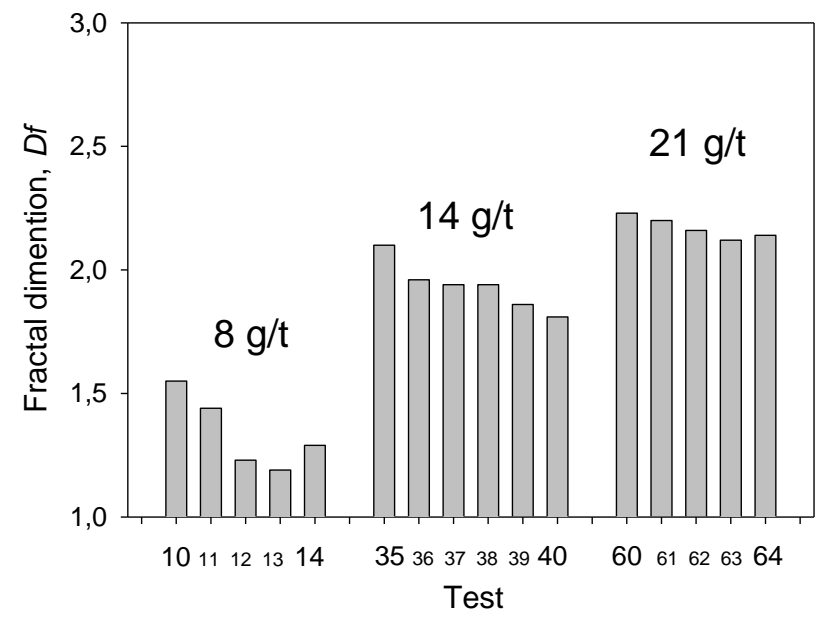

Figure 8. Influence of flocculant dose on fractal dimension of aggregates. The tests numbered in abscissa are according Table 1.

Table 1. Experimental condition at which the tests were performed.

\begin{tabular}{|c|c|c|c|c|c|c|c|c|}
\hline Test & $\begin{array}{l}\text { Flocculant } \\
\text { Doses }(g / t)\end{array}$ & $\begin{array}{l}\text { Mixing Rate } \\
\text { (rpm) }\end{array}$ & $\begin{array}{c}\text { Mixing } \\
\text { Time (s) }\end{array}$ & $D_{f}$ & $\begin{array}{l}\text { Agregate } \\
\text { Size }(\mu \mathrm{m})\end{array}$ & $\begin{array}{c}\text { Initial Settling } \\
\text { Rate }(\mathrm{m} / \mathrm{h})\end{array}$ & $\begin{array}{c}\text { Yield Stress } \\
(\mathbf{P a})\end{array}$ & $\begin{array}{c}\text { Solid } \\
\text { Concentrate }(\%)\end{array}$ \\
\hline 1 & 8 & 100 & 15 & 2.03 & 85 & 2.6 & 116 & 41.9 \\
\hline 3 & 8 & 100 & 45 & 2.06 & 89 & 2.8 & 116 & 43.0 \\
\hline 4 & 8 & 100 & 60 & 1.95 & 79 & 2.2 & 100 & 42.5 \\
\hline 5 & 8 & 100 & 75 & 1.93 & 70 & 2.1 & 95.0 & 43.3 \\
\hline 8 & 8 & 150 & 60 & 1.60 & 94 & 1.5 & 99.6 & 43.1 \\
\hline 9 & 8 & 150 & 75 & 1.50 & 94 & 1.1 & 94.6 & 43.2 \\
\hline 10 & 8 & 225 & 15 & 1.55 & 72 & 1.7 & 106 & 45.6 \\
\hline 11 & 8 & 225 & 30 & 1.44 & 70 & 1.4 & 110 & 45.2 \\
\hline 12 & 8 & 225 & 45 & 1.23 & 62 & 1.2 & 97.0 & 45.0 \\
\hline 13 & 8 & 225 & 60 & 1.19 & 59 & 1.3 & 108 & 45.0 \\
\hline 17 & 14 & 100 & 10 & 3.95 & 48 & 11.4 & 314 & 43.5 \\
\hline 18 & 14 & 100 & 20 & 2.43 & 148 & 10.4 & 318 & 44.2 \\
\hline 19 & 14 & 100 & 30 & 2.40 & 167 & 10.5 & 337 & 42.9 \\
\hline 20 & 14 & 100 & 40 & 2.42 & 137 & 9.5 & 302 & 43.9 \\
\hline 21 & 14 & 100 & 50 & 2.44 & 123 & 8.9 & 295 & 43.7 \\
\hline 22 & 14 & 100 & 60 & 2.43 & 121 & 8.5 & 285 & 43.1 \\
\hline 23 & 14 & 100 & 70 & 2.40 & 121 & 7.8 & 273 & 42.9 \\
\hline 24 & 14 & 100 & 80 & 2.36 & 127 & 7.4 & 242 & 42.8 \\
\hline 25 & 14 & 150 & 10 & 2.25 & 142 & 7.3 & 301 & 44.1 \\
\hline 26 & 14 & 150 & 20 & 2.24 & 214 & 8.1 & 296 & 43.3 \\
\hline 27 & 14 & 150 & 30 & 2.24 & 186 & 7.6 & 330 & 42.7 \\
\hline 28 & 14 & 150 & 40 & 2.18 & 182 & 5.9 & 257 & 43.5 \\
\hline 36 & 14 & 225 & 40 & 1.96 & 113 & 3.0 & 249 & 44.5 \\
\hline 37 & 14 & 225 & 50 & 1.94 & 104 & 2.9 & 226 & 44.6 \\
\hline 38 & 14 & 225 & 60 & 1.94 & 104 & 2.9 & 224 & 44.8 \\
\hline 39 & 14 & 225 & 70 & 1.86 & 98 & 2.4 & 211 & 45.5 \\
\hline 40 & 14 & 225 & 80 & 1.81 & 95 & 2.2 & 208 & 43.4 \\
\hline
\end{tabular}


Table 1. Cont.

\begin{tabular}{|c|c|c|c|c|c|c|c|c|}
\hline Test & $\begin{array}{l}\text { Flocculant } \\
\text { Doses }(g / t)\end{array}$ & $\begin{array}{l}\text { Mixing Rate } \\
\text { (rpm) }\end{array}$ & $\begin{array}{l}\text { Mixing } \\
\text { Time (s) }\end{array}$ & $D_{f}$ & $\begin{array}{l}\text { Agregate } \\
\text { Size }(\mu \mathrm{m})\end{array}$ & $\begin{array}{l}\text { Initial Settling } \\
\text { Rate }(\mathrm{m} / \mathrm{h})\end{array}$ & $\begin{array}{l}\text { Yield Stress } \\
\text { (Pa) }\end{array}$ & $\begin{array}{c}\text { Solid } \\
\text { Concentrate }(\%)\end{array}$ \\
\hline 41 & 14 & 300 & 10 & 1.97 & 119 & 3.8 & 275 & 44.8 \\
\hline 42 & 14 & 300 & 20 & 1.86 & 99 & 3.0 & 250 & 44.2 \\
\hline 43 & 14 & 300 & 30 & 1.82 & 96 & 2.8 & 221 & 44.6 \\
\hline 44 & 14 & 300 & 40 & 1.68 & 91 & 2.1 & 202 & 44.1 \\
\hline 45 & 14 & 300 & 50 & 1.50 & 86 & 1.5 & 163 & 42.5 \\
\hline 46 & 14 & 300 & 60 & 1.66 & 86 & 2.1 & 202 & 45.6 \\
\hline 47 & 14 & 300 & 70 & 1.55 & 84 & 1.7 & 173 & 44.2 \\
\hline 48 & 14 & 300 & 80 & 1.40 & 80 & 1.3 & 159 & 42.8 \\
\hline 49 & 21 & 100 & 10 & 2.77 & 133 & 23.0 & 538 & 41.2 \\
\hline 50 & 21 & 100 & 20 & 2.48 & 195 & 15.5 & 398 & 42.0 \\
\hline 51 & 21 & 100 & 30 & 2.49 & 169 & 14.1 & 357 & 41.8 \\
\hline 52 & 21 & 100 & 45 & 2.38 & 157 & 8.7 & 296 & 44.1 \\
\hline 53 & 21 & 100 & 60 & 2.44 & 149 & 10.6 & 317 & 42.7 \\
\hline 54 & 21 & 100 & 75 & 2.52 & 131 & 11.6 & 336 & 42.9 \\
\hline 55 & 21 & 150 & 15 & 2.32 & 228 & 10.1 & 350 & 41.7 \\
\hline 56 & 21 & 150 & 30 & 2.28 & 188 & 7.9 & 339 & 41.5 \\
\hline 57 & 21 & 150 & 45 & 2.25 & 180 & 6.7 & 322 & 43.4 \\
\hline 58 & 21 & 150 & 60 & 2.20 & 179 & 5.3 & 284 & 42.8 \\
\hline 59 & 21 & 150 & 75 & 2.22 & 183 & 5.9 & 285 & 45.9 \\
\hline 60 & 21 & 225 & 15 & 2.23 & 202 & 7.5 & 369 & 42.7 \\
\hline 61 & 21 & 225 & 30 & 2.20 & 156 & 6.4 & 363 & 42.6 \\
\hline 62 & 21 & 225 & 45 & 2.16 & 135 & 5.5 & 342 & 43.7 \\
\hline 63 & 21 & 225 & 60 & 2.12 & 130 & 4.8 & 313 & 41.6 \\
\hline 64 & 21 & 225 & 75 & 2.14 & 129 & 5.1 & 311 & 43.7 \\
\hline 65 & 21 & 300 & 15 & 2.10 & 146 & 5.7 & 363 & 44.1 \\
\hline 66 & 21 & 300 & 30 & 2.04 & 122 & 4.7 & 330 & 42.3 \\
\hline 67 & 21 & 300 & 40 & 1.95 & 110 & 3.8 & 288 & 43.3 \\
\hline 68 & 21 & 300 & 50 & 2.02 & 104 & 4.5 & 311 & 43.2 \\
\hline 69 & 21 & 300 & 60 & 1.90 & 102 & 3.4 & 287 & 43.1 \\
\hline 70 & 21 & 300 & 70 & 1.79 & 98 & 2.7 & 265 & 42.4 \\
\hline 71 & 21 & 300 & 80 & 1.79 & 95 & 2.8 & 275 & 44.2 \\
\hline
\end{tabular}

\section{Conclusions}

This research aims to analyse the implications of physical conditions of the feedwell on the rheological properties of the underflow of flocculated clay-based tailings in seawater. The mixing intensity was related to the structural characteristics of the aggregates, and the outcomes were linked to the yield stress of the flocculated pulp sediment. Stronger agitations cause a more significant breaking of bonds between the particle/aggregate networks that make up the slurry, before the sedimentation process. This induces the aggregate structures to be more fragile and open; then, higher mixing intensity leads to lower yield stress values. In this context, at a fixed mixing rate, the yield stress presented a seemingly exponential increase over the fractal dimension. Additionally, a direct relationship between the yield stress and the settling rate was found since both parameters depend on the structural characteristic of the particle aggregates. The outcomes provided in this study are of interest to the copper mining industry, especially those that use seawater in their operations.

Author Contributions: All of the authors contributed to analysing the results and writing the paper.

Funding: This research was funded by Conicyt Fondecyt 11171036 and Centro CRHIAM Project Conicyt/Fondap/15130015.

Acknowledgments: Ricardo I. Jeldres thanks Conicyt Fondecyt 11171036 and Centro CRHIAM Project Conicyt/Fondap/15130015. The authors are grateful for the contribution of the Scientific Equipment UnitMAINI of the Universidad Católica del Norte for supporting the experimental tests. Pedro Robles thanks the Pontificia Universidad Católica de Valparaíso for the support provided.

Conflicts of Interest: The authors declare no conflict of interest.

\section{References}

1. Kane, J.C.; La Mer, V.K.; Linford, H.B. The effect of solid content on the adsorption and flocculation behavior of silica suspensions. J. Phys. Chem. 1964, 68, 3539-3544. [CrossRef] 
2. Rudman, M.; Simic, K.; Paterson, D.A.; Strode, P.; Brent, A.; Šutalo, I.D. Raking in gravity thickeners. Int. J. Miner. Process. 2008, 86, 114-130. [CrossRef]

3. Gladman, B.R.; Rudman, M.; Scales, P.J. The effect of shear on gravity thickening: Pilot scale modelling. Chem. Eng. Sci. 2010, 65, 4293-4301. [CrossRef]

4. De Kretser, R.; Scales, P.J.; Boger, D.V. Improving clay-based tailings disposal: Case study on coal tailings. AIChE J. 1997, 43, 1894-1903. [CrossRef]

5. Castillo, C.; Ihle, C.F.; Jeldres, R.I. Chemometric optimisation of a copper sulphide tailings flocculation process in the presence of clays. Minerals 2019, 9, 582. [CrossRef]

6. Du, J.; Morris, G.; Pushkarova, R.A.; Roger, S.C.S. Effect of surface structure of kaolinite on aggregation, settling rate, and bed density. Langmuir 2010, 26, 13227-13235. [CrossRef]

7. Liu, D.; Edraki, M.; Berry, L. Investigating the settling behaviour of saline tailing suspensions using kaolinite, bentonite, and illite clay minerals. Powder Technol. 2018, 326, 228-236. [CrossRef]

8. Jeldres, R.I.; Piceros, E.C.; Wong, L.; Leiva, W.H.; Herrera, N.; Toledo, P.G. Dynamic moduli of flocculated kaolinite sediments: Effect of salinity, flocculant dose, and settling time. Colloid Polym. Sci. 2018, 296, 1935-1943. [CrossRef]

9. Teh, E.J.; Leong, Y.K.; Liu, Y.; Fourie, A.B.; Fahey, M. Differences in the rheology and surface chemistry of kaolin clay slurries: The source of the variations. Chem. Eng. Sci. 2009, 64, 3817-3825. [CrossRef]

10. Nabzar, L.; Pefferkorn, E.; Varoqui, R. Polyacrylamide-sodium kaolinite interactions: Flocculation behavior of polymer clay suspensions. J. Colloid Interface Sci. 1984, 102, 380-388. [CrossRef]

11. Lee, L.T.; Rahbari, R.; Lecourtier, J.; Chauveteau, G. Adsorption of polyacrylamides on the different faces of kaolinites. J. Colloid Interface Sci. 1991, 147, 351-357. [CrossRef]

12. Heath, A.R.; Bahri, P.A.; Fawell, P.D.; Farrow, J.B. Polymer flocculation of calcite: Experimental results from turbulent pipe flow. AIChE J. 2006, 52, 1284-1293. [CrossRef]

13. Spicer, P.T.; Pratsinis, S.E. Shear-induced flocculation: The evolution of floc structure and the shape of the size distribution at steady state. Water Res. 1996, 30, 1049-1056. [CrossRef]

14. Vaezi, G.F.; Sanders, R.S.; Masliyah, J.H. Flocculation kinetics and aggregate structure of kaolinite mixtures in laminar tube flow. J. Colloid Interface Sci. 2011, 355, 96-105. [CrossRef]

15. Kousaka, Y.; Okuyama, K.; Payatakes, A. Physical meaning and evaluation of dynamic shape factor of aggregate particles. J. Colloid Interface Sci. 1981, 84, 91-99. [CrossRef]

16. Gabitto, J.; Tsouris, C. Drag coefficient and settling velocity for particles of cylindrical shape. Powder Technol. 2008, 183, 314-322. [CrossRef]

17. Nguyen, Q.D.; Boger, D.V. Application of rheology to solving tailings disposal problems. Int. J. Miner. Process. 1998, 54, 217-233. [CrossRef]

18. Zhou, Y.; Yu, H.; Wanless, E.J.; Jameson, G.J.; Franks, G.V. Influence of polymer charge on the shear yield stress of silica aggregated with adsorbed cationic polymers. J. Colloid Interface Sci. 2009, 336, 533-543. [CrossRef]

19. Johnson, S.B.; Franks, G.V.; Scales, P.J.; Boger, D.V.; Healy, T.W. Surface chemistry-rheology relationships in concentrated mineral suspensions. Int. J. Miner. Process. 2000, 58, 267-304. [CrossRef]

20. Neelakantan, R.; Vaezi, G.F.; Sanders, R.S. Effect of shear on the yield stress and aggregate structure of flocculant-dosed, concentrated kaolinite suspensions. Miner. Eng. 2018, 123, 95-103. [CrossRef]

21. Suyantara, G.P.W.; Hirajima, T.; Miki, H.; Sasaki, K. Floatability of molybdenite and chalcopyrite in artificial seawater. Miner. Eng. 2018, 115, 117-130. [CrossRef]

22. Jeldres, R.I.; Arancibia-Bravo, M.P.; Reyes, A.; Aguirre, C.E.; Cortes, L.; Cisternas, L.A. The impact of seawater with calcium and magnesium removal for the flotation of copper-molybdenum sulphide ores. Miner. Eng. 2017, 109, 10-13. [CrossRef]

23. Castro, S. Physico-chemical factors in flotation of Cu-Mo-Fe ores with seawater: A critical review. Physicochem. Probl. Miner. Process. 2018, 54, 1223-1236. [CrossRef]

24. Cambridge, M.L.; Zavala-Perez, A.; Cawthray, G.R.; Statton, J.; Mondon, J.; Kendrick, G.A. Effects of desalination brine and seawater with the same elevated salinity on growth, physiology and seedling development of the seagrass Posidonia australis. Mar. Pollut. Bull. 2019, 140, 462-471. [CrossRef]

25. Uddin, S. Environmental impacts of desalination activities in the Arabian gulf. Int. J. Environ. Sci. Dev. 2014, 5, 114-117. [CrossRef] 
26. Reyes, C.; Álvarez, M.; Ihle, C.F.; Contreras, M.; Kracht, W. The influence of seawater on magnetite tailing rheology. Miner. Eng. 2019, 131, 363-369. [CrossRef]

27. Jeldres, R.I.; Piceros, E.C.; Leiva, W.H.; Toledo, P.G.; Herrera, N. Viscoelasticity and yielding properties of flocculated kaolinite sediments in saline water. Colloids Surf. A Physicochem. Eng. Asp. 2017, 529, 1009-1015. [CrossRef]

28. Quezada, G.R.; Jeldres, R.I.; Fawell, P.D.; Toledo, P.G. Use of molecular dynamics to study the conformation of an anionic polyelectrolyte in saline medium and its adsorption on a quartz surface. Miner. Eng. 2018, 129, 102-105. [CrossRef]

29. Gladman, B.; de Kretser, R.G.; Rudman, M.; Scales, P.J. Effect of shear on particulate suspension dewatering. Chem. Eng. Res. Des. 2005, 83, 933-936. [CrossRef]

30. Bubakova, P.; Pivokonsky, M.; Filip, P. Effect of shear rate on aggregate size and structure in the process of aggregation and at steady state. Powder Technol. 2013, 235, 540-549. [CrossRef]

31. Biggs, C. Activated sludge flocculation: On-line determination of floc size and the effect of shear. Water Res. 2000, 34, 2542-2550. [CrossRef]

32. Kyoda, Y.; Costine, A.D.; Fawell, P.D.; Bellwood, J.; Das, G.K. Using focused beam reflectance measurement (FBRM) to monitor aggregate structures formed in flocculated clay suspensions. Miner. Eng. 2019, 138, 148-160. [CrossRef]

33. Heath, A.R.; Bahri, P.A.; Fawell, P.D.; Farrow, J.B. Polymer flocculation of calcite: Relating the aggregate size to the settling rate. AIChE J. 2006, 52, 1987-1994. [CrossRef]

34. Benn, F.A.; Fawell, P.D.; Halewood, J.; Austin, P.J.; Costine, A.D.; Jones, W.G.; Francis, N.S.; Druett, D.C.; Lester, D. Sedimentation and consolidation of different density aggregates formed by polymer-bridging flocculation. Chem. Eng. Sci. 2018, 184, 111-125. [CrossRef]

35. Heath, A.R.; Fawell, P.D.; Bahri, P.A.; Swift, J.D. Estimating average particle size by focused beam reflectance measurement (FBRM). Part. Part. Syst. Charact. 2002, 19, 84. [CrossRef]

36. Fawell, P.D.; Nguyen, T.V.; Solnordal, C.B.; Stephens, D.W. Enhancing gravity thickener feedwell design and operation for optimal flocculation through the application of computational fluid dynamics. Miner. Process. Extr. Metall. Rev. 2019,1-15. [CrossRef]

37. Deng, X.; Davé, R.N. Breakage of fractal agglomerates. Chem. Eng. Sci. 2017, 161, 117-126. [CrossRef]

38. Kendall, K.; Stainton, C. Adhesion and aggregation of fine particles. Powder Technol. 2001, 121, $223-229$. [CrossRef]

39. Zhou, Y.; Gan, Y.; Wanless, E.J.; Jameson, G.J.; Franks, G.V. Interaction forces between silica surfaces in aqueous solutions of cationic polymeric flocculants: Effect of polymer charge. Langmuir 2008, 24, 10920-10928. [CrossRef]

40. Tang, P.; Greenwood, J.; Raper, J.A. A model to describe the settling behavior of fractal aggregates. J. Colloid Interface Sci. 2002, 247, 210-219. [CrossRef]

41. Ofori, P.; Nguyen, A.V.; Firth, B.; McNally, C.; Ozdemir, O. Shear-induced floc structure changes for enhanced dewatering of coal preparation plant tailings. Chem. Eng. J. 2011, 172, 914-923. [CrossRef]

(C) 2019 by the authors. Licensee MDPI, Basel, Switzerland. This article is an open access article distributed under the terms and conditions of the Creative Commons Attribution (CC BY) license (http://creativecommons.org/licenses/by/4.0/). 